\title{
Epidemiological study of spine cases admitted at Grande International Hospital
}

Javed Ahmad Khan, MS; Binod Bijukachhe, MS; Gyanendra Joshi, MS; Ram Krishna Dahal, MS Spine services, Department of Orthopedics, Grande International Hospital, Kathmandu, Nepal

\section{Corresponding author}

Dr. Javed Ahmad Khan, MS

Email:drjaved123@yahoo.com

Received 21 Feb 2019

Accepted 15 May 2019

ABSTRACT
Introduction
Our institution is tertiary care centre and referral centre for spine surgery. We like to share the
epidemiological parameters of the case treated here.
Methods
This is retrospective, descriptive study conducted from 2013 to August 2018 . All the data retrieved
from hospital information system of admitted patients and demographic presentations, disease
pattern, region of involvement were analyzed.
Result
There were a total of 698 patients. Male were $262(37.5 \%)$ and female were $436(62.5 \%)$. Age wise
distribution ranged from 2 years to 85 years. Maximum numbers of patients were from 31 to 60
years (57.5\%) and there were only $3 \%$ of cases less than 15 years and above 76 years. $30.2 \%$ cases
were related to trauma, $29.8 \%$ of cases were related to disc pathology, followed by degenerative
diseases $13 \%$, infection $9.2 \%$, and $5.4 \%$ were of tumors $8.7 \%$ were cases were not classified in the
above categories. There were $56.7 \%$ cases from lumbosacral region, $16.3 \%$ cases from thoracic
region, $13.2 \%$ cases from cervical region, $5.7 \%$ cases were from multiple regions. $0.3 \%$ were of
generalized nature which could not be classified.
Conclusion
Spinal diseases are more common in female population, more frequent in third to sixth decade of
life. Highest numbers of cases were from traumatic cause followed by degenerative disc diseases.
Lumbosacral region is most commonly affected.
Keywords: Spine, Cases, Epidemiological Study

\section{Introduction}

Back pain is a common health problem, with over two thirds of adults suffering from it over their lifetime ${ }^{1}$. Back pain accounts for significant amount of health care cost in developed countries ${ }^{2}$. However, little information regarding back pain epidemiology is available in Nepal.

In most back pain cases, a clear pathoanatomical cause cannot be identified. So it is really difficult to specify specific approach to reduce these event ${ }^{2}$. There are studies which tried to point out the causes of back pain but results are inconclusive ${ }^{3}$. Disc degeneration has long been thought to be a major cause $e^{4}$. Yet most studies do not reveal strong associations between disc degeneration and back pain ${ }^{5}$. 


\section{Methods}

This is a cross-sectional study of sample of patients with back problems admitted to the spine department. Patient data from April 2013 to August 2018 were retrieved from hospital information system. Patients were categorized in the diseases pattern which was divided into Trauma, Degenerative, Disc disease, Deformity, Infection, Tumors and Others.

Trauma cases included all non-pathological spine fractures and soft tissue injuries. Degenerative conditions included cervical and lumbar spondylosis, spinal canal and root canal stenosis, ossification of posterior longitudinal ligament (OPLL) and yellow ligament, spondylolisthesis, segmental instability. Disc diseases included disc prolapse, annular tear. Deformity included scoliosis and sagittal plane deformities. Infection included spondylodiscitis, vertebral osteomyelitis, epidural abscess, post-operative spine infection of pyogenic or tubercular origin. Tumors included all the primary or metastatic, benign or malignant tumors affecting the spine. It included vertebral, extradural, intradural tumors. Those conditions which could not be classified in above categories were classified into others eg. spondyloarthopathy, mechanical backache, hydatid disesase.

Regional distribution from basiocciput to C7 vertebrae were classed in cervical region, from T1 to T12 level in thoracic region, from L1 including sacrum and coccyx in lumbosacral region. When involvement occurred in junctional region or more than one region then they were classed in multiple regions. Conditions associated with generalized or systemic disease were considered in 'others' group.

\section{Results}

There were a total of 698 patients, 262 males (37.5\%), 436 females (62.5\%). Age ranged from 2 years to 85 years. Maximum numbers of patients ranged from 31 to 60 years $(57.5 \%)$ and there were only $3 \%$ of cases less than 15 years and above 76 years. $30.2 \%$ cases were related to trauma, $29.8 \%$ of cases were related to disc pathology, followed by degenerative diseases $13 \%$, infection $9.2 \%$, and $5.4 \%$ tumors. $8.7 \%$ cases were not classified in the above categories. There were $56.7 \%$ cases from lumbosacral region, $16.3 \%$ cases from thoracic region, $13.2 \%$ cases from cervical region, $5.7 \%$ cases were from multiple regions. $0.3 \%$ was of generalized nature which could not be classified.
Table1: Age-wise distribution

\begin{tabular}{|c|c|}
\hline Age & $\mathbf{n}(\%)$ \\
\hline$\leq 15$ & $21(3)$ \\
\hline $16-30$ & $148(21.2)$ \\
\hline $31-45$ & $237(34)$ \\
\hline $46-60$ & $164(23.5)$ \\
\hline $61-75$ & $107(15.3)$ \\
\hline 76 and above & $21(3)$ \\
\hline Median age $\left(\mathbf{Q}_{3}-\mathbf{Q}_{\mathbf{1}}\right)$ & $42(55-31)$ \\
\hline $\begin{array}{c}\text { Minimum age , Maximum age } \\
\text { (Range) }\end{array}$ & $2,85(83)$ \\
\hline
\end{tabular}

Table 2: Gender-wise patient categorization

\begin{tabular}{|l|c|}
\hline Gender & $\mathbf{n}(\%)$ \\
\hline Female & $262(37.5)$ \\
\hline Male & $436(62.5)$ \\
\hline
\end{tabular}

Table 3: Year-wise patient distribution

\begin{tabular}{|c|c|}
\hline Year & $\mathbf{n}(\%)$ \\
\hline 2013 & $63(9)$ \\
\hline 2014 & $86(12.3)$ \\
\hline 2015 & $55(7.9)$ \\
\hline 2016 & $150(21.5)$ \\
\hline 2017 & $207(29.7)$ \\
\hline Until August 2018 & $137(19.6)$ \\
\hline Total & $\mathbf{6 9 8 ( 1 0 0 )}$ \\
\hline
\end{tabular}

Table 4: Disease Categorization

\begin{tabular}{|l|c|}
\hline \multicolumn{1}{|c|}{ Disease category } & $\mathbf{n ~ ( \% )}$ \\
\hline Degenerative disc disease & $208(29.8)$ \\
\hline Deformity & $25(3.6)$ \\
\hline Degenerative & $91(13)$ \\
\hline Infection & $64(9.2)$ \\
\hline Others & $61(8.7)$ \\
\hline Trauma & $211(30.2)$ \\
\hline Tumor & $38(5.4)$ \\
\hline
\end{tabular}

Table 5: Anatomical regional distribution

\begin{tabular}{|l|c|}
\hline \multicolumn{1}{|c|}{ Region } & $\mathrm{n}(\%)$ \\
\hline Cervical & $92(13.2)$ \\
\hline Thoracic & $114(16.3)$ \\
\hline Lumbar & $396(56.7)$ \\
\hline Multilevel & $40(5.7)$ \\
\hline Others & $2(0.3)$ \\
\hline
\end{tabular}




\section{Discussion}

Till date there has been no population-based study specifically designed to investigate the lumbar spine and back health of people in Nepal. The epidemiological characteristics of back pain remain largely unexplored. However, there is enormous health problem related to back pain and the government has no specific program to address this issue ${ }^{6}$. To complement knowledge in this area, we compiled this spine audit. In this paper, we include demographic parameters, disease pattern, and regional involvement.

Our center is a tertiary referral center which receives not only daily walk-ins and emergencies but also a lot of cases that could not be managed elsewhere. We have included all the cases admitted under 'Spine Services' in our hospital. The documentation system is state-of-the art electronic medical record system enabling us in compiling accurate data. We hope that this audit will help future researchers from Nepal.

\section{Conclusion}

Spinal diseases are more common in female population. Spine cases requiring admission is more frequent in young adults and middle aged population. Highest numbers of cases were from traumatic cause followed by degenerative disc diseases. Lumbosacral region is the most commonly affected.

\section{References}

1. Deyo RA, Weinstein JN. Low Back Pain. N Engl J Med. 2011;344(5):363-70.

2. Andersson GBJ. Epidemiological features of chronic low-back pain. The Lancet. 1999;354:581-5.

3. Balagué $F$, Mannion AF, Pellisé F, Cedraschi C. Non-specific low back pain. The Lancet. 2012;379(9814):482-91.

4. Battié MC, Videman T. Lumbar disc degeneration: epidemiology and genetics. J Bone Joint Surg Am. 2006;88(2):3-9.

5. Jensen MC, Brant-Zawadzki MN, Obuchowski $\mathrm{N}$, Modic MT, Malkasian D, Ross JS. Magnetic resonance imaging of the lumbar spine in people without back pain. N Engl J Med. 1994;331(2):69-73.

6. Shrestha B, Niraula S, Khanal G, Karn N., Chaudhary P, Rijal R, Maharjan, R. Epidemiology of back pain in the teaching districts of B. P. Koirala Institute of Health Sciences. Health Renaissance. 2011;9(3):152-6. 